\title{
Health Care Providers' Experience with a Protocol for the Identification, Treatment, and Referral of Human-Trafficking Victims
}

\section{Citation}

Stoklosa, Hanni, Elizabeth Showalter, Anna Melnick, and Emily F. Rothman. 2016. "Health Care Providers' Experience with a Protocol for the Identification, Treatment, and Referral of Human-Trafficking Victims." Journal of Human Trafficking 3 (3) (October 8): 182-192. doi:10.1080/23322705.2016.1194668.

\section{Published Version}

doi:10.1080/23322705.2016.1194668

\section{Permanent link}

http://nrs.harvard.edu/urn-3:HUL.InstRepos:34638822

\section{Terms of Use}

This article was downloaded from Harvard University's DASH repository, and is made available under the terms and conditions applicable to Other Posted Material, as set forth at http:// nrs.harvard.edu/urn-3:HUL.InstRepos:dash.current.terms-of-use\#LAA

\section{Share Your Story}

The Harvard community has made this article openly available.

Please share how this access benefits you. Submit a story. 
Healthcare providers' experience with a protocol for the identification, treatment and referral of human trafficking victims

Hanni Stoklosa, MD, MPH

Elizabeth Showalter

Anna Melnick

Emily F. Rothman, ScD

March 17, 2016

Word count: 5,440 


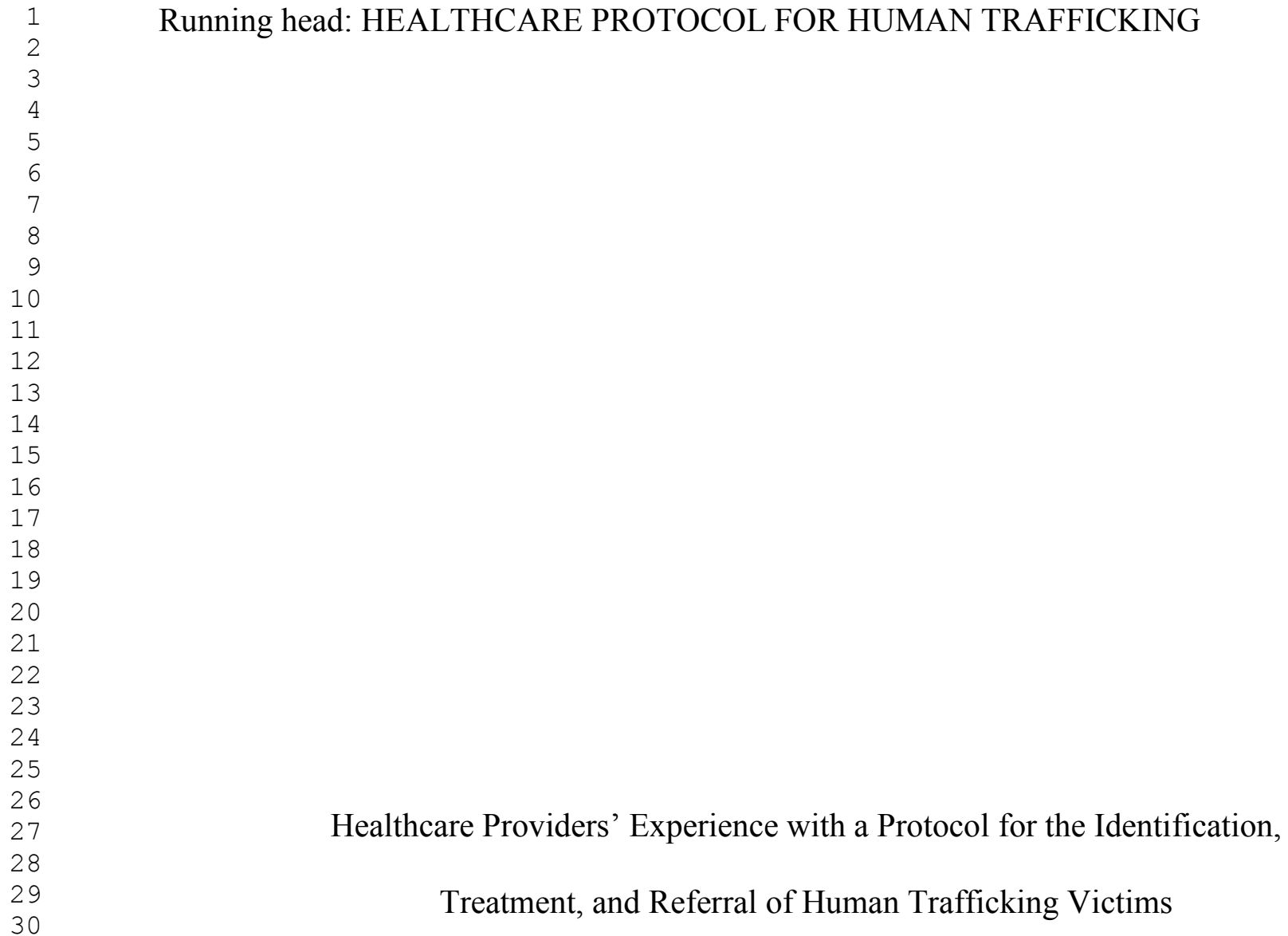

Treatment, and Referral of Human Trafficking Victims

May 18, 2016

Word count: 5,440 


\begin{abstract}
The healthcare setting is thought to be one of the most promising places to identify victims of human trafficking. The present study was designed to relay the experiences of a sample of 10 healthcare providers and hospital administrators who developed and have used a protocol to identify victims of human trafficking since February 2014. To our knowledge, the protocol was one of the first to be adopted by any healthcare system in the U.S. Three primary themes emerged from the participant interviews. First, developing the protocol was challenging because at the time there were no predecessor examples. Second, providers reported that the protocol is simple to use and victim identification is easier because of it. Third, identifying and serving victims of human trafficking remains challenging, because there is still a deficit of trained providers and a lack of community resources for survivors. The field needs evidence that this and similar protocols improve users' knowledge and skills, result in the better identification and treatment of trafficking victims, and ultimately improve public safety and public health.
\end{abstract}

Keywords: human trafficking, healthcare protocol, exploitation, trauma-informed care, violence victims

Acknowledgments: The authors would like to thank the Via Christi Health, Inc. with particular thanks to Nicole Ensminger, the Human Trafficking Program Manager. 


\section{Healthcare Providers' Experience with a Protocol for the Identification, Treatment, and Referral of Human Trafficking Victims}

\section{Introduction}

Human trafficking is defined as the act of recruiting, harboring, transporting, providing, or obtaining a person for compelled labor or commercial sex acts through the use of force, fraud, or coercion (U.S. Department of State, 2015). Although establishing the number of human trafficking victims is extraordinarily challenging, it has been estimated that more than 20 million people worldwide are presently victims of forced labor and/or sex trafficking (U.S. Department of State, 2014). Human trafficking has been declared the second largest criminal enterprise in the world, generating an estimated $\$ 150$ billion USD per year (International Labor Organization, 2015), and is therefore considered one of the most pressing global human rights, law enforcement, and public health problems. U.S. President Barak Obama and the Clinton Global Initiative have stated that "our fight against human trafficking is one of the great human rights causes of our time" (The White House, 2015), and the U.S. is presently in the middle of executing a five-year federal strategic action plan on services for victims of human trafficking (President's Interagency Task Force to Monitor and Combat Trafficking in Persons, 2013).

The total number of human trafficking victims ${ }^{1}$ in the U.S. is unknown, but in 2014 there were 8,414 victims identified in the Western Hemisphere, including Canada, the U.S., Mexico, Central and South America, and the U.S. Department of Justice charged 335 defendants with trafficking through 208 prosecutions (U.S. Department of State, 2015). A major problem in trafficking scholarship and activism is that the number of victims estimated ranges widely, and

\footnotetext{
${ }^{1}$ An individual who is trafficked may at different stages identify more closely with the term victim or survivor. In this document, we referred to all trafficked persons as victims for consistency.
} 
the U.S. has been criticized for expending hundreds of millions of dollars to combat the issue when only hundreds of confirmed victims are identified in the nation each year (Weitzer, 2015). Some allege that the magnitude and seriousness of the problem have been overestimated (Weitzer, 2014), while others insist that the tremendous difficulty of identifying victims and the inadequate readiness of law enforcement to investigate potential cases may be responsible for the low number of identified victims (Farrell, McDevitt, \& Fahy, 2010).

The healthcare setting: A new venue for identifying victims of trafficking

The healthcare setting is thought to be one of the most promising places to identify victims of trafficking, because victims are sometimes brought to healthcare facilities for treatment of injuries or illness - as many as $30-88 \%$ of U.S. trafficking victims are believed to receive healthcare at least once during their captivity (Konstantopoulos et al., 2013; Lederer \& Wetzel, 2014; Peters, 2013). In some cases, healthcare professionals may be the sole individuals to come into contact with the victim who have the capacity to help them (Baldwin, Eisenman, Sayles, Ryan, \& Chuang, 2011; Ernewein \& Nieves, 2015; Sabella, 2011). The problem is that relatively few healthcare professionals know how to identify victims of sex trafficking amongst their patients, and even fewer have received clear guidance on what to do when they suspect a patient is a victim (Chisolm-Straker, Richardson, \& Cossio, 2012; Stoklosa, Grace, \& Littenberg, 2015).

One recent survey of 180 emergency medicine providers in the U.S. found that only $5 \%$ had ever been trained on how to respond to victims of human trafficking (Chisolm-Straker et al., 2012). A similar U.K.-based study surveyed 782 healthcare professionals and found that $20 \%$ had received any training on human trafficking (Ross et al., 2015). Perpetrators may present as caring, well-spoken family members or romantic partners when they accompany their victims to 
healthcare settings, making identification of victims by healthcare professionals that much more challenging (Becker \& Bechtel, 2015). To address the problem of identifying and assisting victims of human trafficking, some hospitals and human service agencies have either developed or are in the process of developing training and/or guidelines for staff (Grace, Ahn, \& Konstantopoulos, 2014), but the number of U.S. hospitals with such guidelines in place as of November 2015 is estimated to be less than 1\% (Barrows, 2015). A review of training materials for healthcare staff on the identification and treatment of victims of human trafficking found only 27 in existence worldwide, and none of these had been rigorously evaluated (Ahn et al., 2013). Despite two subsequent evaluations of trainings that assessed clinicians' improvement in knowledge about human trafficking, there is no information available about whether training results in improvements in victim identification and whether identification ultimately improves victims' health (Aimee M. Grace et al., 2014). However, the results of several recent small-scale studies, and the U.S. Federal Strategic Action Plan on Services for Victims of Human Trafficking, have concluded that education, training and guidance for healthcare professionals on the identification and referral of victims of human trafficking is urgently needed (Ahn et al., 2013; Becker \& Bechtel, 2015; Chisolm-Straker et al., 2012; Aimee M. Grace et al., 2014; President's Interagency Task Force to Monitor and Combat Trafficking in Persons, 2013; Ross et al., 2015).

The present study was designed to relay the experiences of healthcare providers who have been using a protocol to identify victims of human trafficking since February 2014. To our knowledge, the protocol was one of the first to be adopted by any healthcare system in the U.S., so the staff has had a relatively lengthy experience with it. The insights that they have accumulated over the two years since the protocol was put in place are offered for the benefit of 
other healthcare entities that are also working to develop, use, or evaluate guidelines for the identification, treatment and referral of human trafficking victims. A major strength of this study is that the research team is external to the study participants' institution, were uninvolved with the protocol development, and are not engaged in the on-going use of the protocol.

\section{Methods}

\section{Sample and setting}

Participants in this study were staff of a large, urban hospital and healthcare system located in the mid-western U.S. The hospital was identified as a human trafficking protocol pioneer site by a well-established international anti-sex trafficking nonprofit (i.e., Hope for Justice). For the present study, the clinician who led the initiative to develop the protocol at the hospital used a purposive strategy to identify six colleagues to be contacted for inclusion in this study. These individuals were selected by the initiative leader because she believed that they had at least some experience with the protocol and a diversity of opinions about it. Additional participants were recruited for more interviews until data saturation was reached; that is no new information was being uncovered. To identify additional potential interview participants, a snowball sampling method was used - the original seed of six interview participants identified peers as potential participants, who were subsequently contacted and invited to participate in the study. Of 13 nominated individuals, $77 \%(n=10)$ chose to participate in the study. Participants were $40 \%$ administrators or developers of the protocol, $30 \%$ forensic nurses, and $30 \%$ social workers.

\section{Procedures}

A qualitative interview schedule was developed collaboratively by all four authors. The full schedule is available upon request from the fourth author. The interview questions and 
probes were open-ended, and were designed to assess what types of experiences the participants had using the human trafficking protocol for the identification, referral and treatment of victims, and elicited their valuations of it. An example question is: "How, if at all, have you used this protocol in your own work?" Two research assistants (RA) were trained by an experienced qualitative researcher to conduct one-on-one interviews with study participants over the phone. It was determined that audio-recording the interviews would not provide a substantial advantage over note-taking, and note-taking offered the advantage of keeping the study anonymous for participants and the study exempt from IRB review. Therefore, each interview was conducted by one RA who recorded participants' responses in note form, and later transferred those notes into a centralized repository of data for analysis. Data were cleaned of any potentially personally identifying information before analysis (e.g., participants' names or length of tenure in their professional role). Prior to beginning each interview, the RAs emailed an explanation of the study and research participation request to each potential participant, and then arranged an interview date. Immediately preceding each interview, the RA read a short, standardized explanation of who was conducting the study, the study purpose, who was being invited to participate in the study, and the confidentiality parameters. Participants had an opportunity to consider declining participation in the interview and they were told that they could skip any questions that they did not want to answer. Study procedures were reviewed and determined to be exempt by the [institution name redacted for blind review] institutional review board (IRB).

\section{The protocol}

The objective of this study was to gather information about the development and implementation of a healthcare system protocol for identifying, referring and treating victims of human trafficking. In this case, the term "protocol" refers to a set of indicators of possible 
victimization that providers should consider while treating every patient, and a series of four steps to take when vicitmization is suspected. The indicators and steps are outlined on a small, easy-to-read pocket-card that clinicians can carry and consult (see Appendix). Importantly, the word "trafficking" does not appear on the pocket-card so that if it is seen by a patients it is not immediately recognizable as a trafficking protocol. The protocol contains both a "screening tool" which is meant to be applied to all patients, even those showing no obvious signs of trafficking victimization, and the series of four actions to take if a potential victim is identified. Through a brief, online training module, and in some cases an all-day in-person training, clinicians in all hospital departments and community healthcare clinics are trained to assess all patients using the screening indicators; they are advised to look for any of eight physical indicators of trafficking victimization (e.g., unusual occupational injuries, multiple pregnancies or abortions, branding tattoos), nine warning signs called "red flags" (e.g., discrepancy between the history and clinical presentation), and seven indicators the patient is being controlled by someone else (e.g., accompanying person does not allow patient to answer questions). If any physical indicators, red flags, or control indicators are present, clinicians are advised to proceed through the four steps of the protocol. The steps include: (1) Notifying a forensic nurse, and following a domestic violence or child abuse protocol, depending upon the patient's age; (2) Having a trauma-informed professional interview the patient using trafficking victimization risk factor questions (e.g., "Do you have to meet a quota of money before you can go home?"); (3) Consider filing a child abuse report if the patient is younger than 18 years old and it is determined to be a trafficking case, or if an adult, ask his or her interest in involving law enforcement or receiving other forms of assistance; and (4) Consider additional referral options, including national hotline numbers such as the National Human Trafficking Resource Center 
hotline; and assure adults who decline assistance that it will continue to be available to them 24 hours a day. The hospital is tracking how often the protocol is being used, so information about how consistently providers are screening patients - and whether the consistency in screening varies by clinical department—will be forthcoming.

\section{Analysis}

This study used a content analysis approach (Hsieh \& Shannon, 2005), and adhered to the RATS qualitative research guidelines (Relevance of study question, Appropriateness of qualitative methods, Transparency of procedures, Soundness of interpretive Approach) (Clark, 2003). First, research assistants (RAs) read through all data multiple times to "achieve immersion" and get a sense of the whole (Hsieh \& Shannon, 2005). Next, codes were derived from the text to describe key themes that emerged. Each RA applied the codes to "chunks of text" (e.g., sentences or phrases) throughout the entire raw data document, and then discussed any chunks where they had not applied the same code to come to a consensus coding. Of the 68 chunks of text coded, the two independent raters had $96 \%$ agreement. Chunks of text were sorted by code category and categories were grouped together logically-i.e., reactions to using the protocol, or challenges associated with assessing patients for trafficking victimization. The categories were read through again in order to confirm that the coded sections of text in each were a good fit for that category, and so that inferences could be drawn. Particularly illustrative quotations for each category were selected and are presented in the results section.

\section{Results}

Three primary themes emerged from the participant interviews. First, developing the protocol was challenging because at the time there were no predecessor examples and multiple stakeholders needed to vet the protocol. Second, providers reported that the protocol is simple to 
use and that it makes victim identification easier. Third, challenges remain, including challenges related to training, maintaining a multi-disciplinary team, and the lack of community resources for victims. These themes are explored in greater detail below.

\section{Theme 1: Protocol development was challenging}

In 2013, a three-person core protocol development team came together to develop the healthcare system's human trafficking protocol. There were no other hospital or healthcare system protocols available to use as a model. The core team drew upon existing research, their professional experience, and national resources (e.g., guidance from the non-profit Polaris), to draft an initial version of the protocol. The protocol was put into use in February 2014. Next, while the field test of the draft protocol was underway, the core team expanded by inviting members of forensic nursing, security, emergency medicine, communications, patient education, and social work to join the effort. The expanded team partnered with law enforcement professionals external to the hospital, and the internal legal department, to make sure the draft protocol conformed to local laws and healthcare system policies. A nationally-recognized expert in providing medical care to human trafficking victims was also consulted, as was the local district attorney. Subsequently, updates were made to the protocol and it was re-released in March 2015. The main updates were changes to the pocket-card that specified trauma-informed interviewers were needed to assess the patients, and that additional assessment questions were likely going to be needed in cases involving foreign nationals. In June 2015, the protocol was disseminated to other hospitals and community-based clinics in the vicinity that are part of the same healthcare network. Further dissemination to hospitals in the same network in 22 U.S. states is planned to occur in the near future. 
When the protocol was first implemented, provider training on the protocol was encouraged but not required. Subsequently the training became mandatory for all clinician employees of the healthcare system (i.e., clinicians in any position and in any department), because there is an expectation that all clinicians will be assessing all patients for possible victimization. By 2015 more than 8,000 individuals had participated in the online version of the training, which is often supplemented by live simulations of screening a patient for victimization. There is also a day-long in-person training about how to use the protocol, and several hundred clinicians, including physicians, nurses, social workers, and others, have participated in that daylong training by March 2016. It is not clear how many individuals trained online, or in the daylong training, follow through with consistent screening, but the hospital does attempt to track the use of the actions steps portion of the protocol. Presently, three forensic nurses have access to a secure Excel database where data about the suspected human trafficking identification and referral incidents are stored. The database includes variables such as the patient's age, who referred the patient to the healthcare site, and what responses the patient gave to the protocol assessment questions.

Many study participants commented that it was both exciting and draining to be involved in a pioneering effort - they felt it was an important task, but had to find time to engage in the process on top of their full-time work. As one senior administrator said:

"...clinicians are in a unique position to intervene to help identify victims, but [when we developed our protocol] there were no training programs or protocols to do this."

A social worker commented that although she believed that her colleagues from across the country likely knew they were treating trafficking victims, it felt like a "new topic" 
that "no one has ever really addressed." Recalling the protocol development period, she commented:

"You knew it was going on, but no one had stepped up and addressed it." Some felt that human trafficking was a "unique" topic that required a new kind of planning during the protocol development phase, which partially explains why the pioneering effort was time-consuming. One external consultant, an expert in trafficking, said:

"[A human trafficking protocol is] far more involved [than a domestic violence protocol] and requires a fair amount of investment in terms of time and manpower to get a full-bodied and fully disciplined protocol."

\section{Theme 2: The protocol is easy to use and helps clinicians identify victims}

All of the participants found the updated protocol easy to use, visually attractive, simple to conceal in a pocket and consult as needed, and were convinced it had led to the detection of more trafficking victims. The clinicians reported feeling more confident about their capacity to assess patients for victimization after receiving protocol-related training, and were generally more mindful about the possibility that they were treating trafficking victims. In fact, two participants reported that once the protocol was in use, providers started realizing that they had likely missed prior cases. Describing the training sessions, one hospital administration consultant commented:

"I saw people thinking through cases that had been missed."

Similarly, a forensic nurse recalled feeling rueful during her training:

"I thought, 'Wow, we have been letting a lot of victims slide through the door because of lack of knowledge.'...I wish [the protocol] had come a long time ago." 
A social worker described herself as much more aware of the possibility that patients were trafficking victims, and cognizant of the fact that patients almost always present with a condition that seems unrelated to trafficking. In her words:

"I am now more hypervigilant...as I see people falling through the cracks all of the time because the initial presenting complaint may be, and is likely to be, completely unrelated to human trafficking."

As for the ease-of-use of the protocol, one social worker commented that it was "userfriendly" and that she was in the habit of referring to it often:

"The protocol is user-friendly, and it becomes second nature after a while...I will refer back to the protocol specifically for patients where I'm unsure of what's going on, because I want to be sure and set the situation up for success by ruling out other things."

There was an overwhelming sense that all of the participants - administrators, physicians, nurses and social workers alike - found the protocol valuable and that it enhanced victim identification, treatment and referral. As one forensic nurse commented:

"A lot of hospitals don't have this. If they do get it, they are going to be amazed and think back and think that they have missed a lot of people."

\section{Theme 3: Victim identifications and referral challenges remain}

Despite their glowing endorsement of the protocol, a number of participants explained that some hurdles remain. In particular, all hospital and health center staff are pressed for time, so expecting people to voluntarily participate in human trafficking-related training may be unreasonable. On the other hand, persuading upper-level decision-makers that training on human trafficking should be mandatory seemed like a distant possibility, given the range and number of healthcare issues that require continuing education or training. Convincing some administrators, and some clinicians, that human trafficking is a sufficiently prevalent problem to 
merit training time is not always straightforward. The problem with too few personnel receiving too little training on trafficking and the protocol is that it requires a team effort to address a single suspected case of trafficking victimization. Multiple players, including nurses, physicians, security, social workers, and interpreters may need to be involved and it is critical that they share the same base knowledge about the warning signs of trafficking, the needs of victims, the potential dangers of perpetrators, and the ethical and legal requirements. Therefore, resolving how many clinicians are trained, and whether it is left voluntary or becomes required, is important. One nurse with specialty-training in sexual assault opined:

"I would like to see mandatory training for each department, even pediatrics...I don't feel that online training is enough, because people will just rush through it to get it done."

A forensic nurse echoed this sentiment, but spoke to the challenges of educating providers:

"It's hard to educate medical providers because they're so busy and they have their everyday focus...some are very interested in the issue and some feel like the extra training is a burden."

Another hospital administrator spoke about the importance of having the buy-in of decision-makers:

"[It is important to] have support from key administrators to have them recognize human trafficking as a priority and worthy of focus...For planning and training, having a supportive administration is necessary to schedule the time for training and to also have it become required."

While speaking about the importance of having multiple personnel trained to know how to identify and respond to patients who may have been trafficked, one administrator explained that a sole trained provider in a healthcare setting may not be able to put his or her training into action because of fear of doing the wrong thing: 
“One doesn't want people to talk themselves out of activating the protocol if they're nervous that they'll make a mistake or make a wrong decision, so having it be a team effort is useful and important."

This sentiment was mirrored by a social worker, who explained that being a member of fully trained team was reassuring and encouraged her to be proactive about trafficking because solving the problem was a shared responsibility. In her words:

"I don't have to be the expert in the clinic, I just have to know who to call if I identify someone."

Another concern expressed was that there were too few local social services equipped to help trafficking survivors. In other words, even when victims were identified by a clinical team, there was a worry that there was no good "next step" in place to help that person. Several participants alluded to the fact that trafficking victims often needed referrals for multiple issues, which might include substance abuse treatment, behavioral health, trauma recovery, occupational training, housing assistance, and continuing education. While the hospital has now established strong partnerships with a variety of service providers prepared to assist trafficking survivors--including detox, counseling, and housing service providers - in 2013-2014 not all of these community-based services had availability for trafficking survivors, and not all of the service providers were yet trained to respond appropriately to some of the unique needs of trafficking survivors (e.g., post-traumatic stress disorder symptoms). As one clinician commented:

"The next frontier,...is to help the community develop an integrated social network to help victims recover."

Similarly, a social worker said: 
"[Human trafficking victims] have a lot of comorbidities, psychiatric needs, severe medical issues... [so it is important to be] kind of looking at the problem from all those different levels...how do we make sure they are taken care of at all of those levels.

A different social worker explained that a compelling reason for creating an integrated community response would be better case coordination through tracking. She said:

"I think we have an excellent protocol. If anything [needed to change] it would be being able to work more closely with the rest of the community...We can track a patient within our hospital system.. but if someone goes to [another hospital]...we have no way to track them."

One forensic nurse summarized the frustration with the paucity of resources for victims that many participants seemed to feel as follows:

"Patients have no where to go once identified if the shelters are full. There is no system in place after they are identified, and nothing is mandatory. There is nothing in place if the patient wants to get out of the situation unless they has a medical condition that would require an in-patient admission. Calling law enforcement doesn't really do anything, because they are working with the same resources as the forensic nurse team has available to them."

\section{Discussion}

Healthcare professionals are increasingly aware that human trafficking affects patient populations around the globe, and many are eager to learn how they can do a better job of identifying, treating and referring victimized patients to helping resources. While some may be skeptical that human trafficking is prevalent enough to warrant physician and other clinician training time, the availability of an easy-to-use, visually appealing, and inexpensive pocket-card screening and action protocol may help allay concerns that it would be too resource-intensive to address the issue. Given the positive experiences of the providers and administrators who participated in this study, the dissemination of the existing protocol for pilot-testing elsewhere 
could be useful to healthcare organizations that presently have no standard operating procedure for identifying or treating trafficking victims.

Identifying and helping victims of human trafficking is important—not only for those individuals' health, but often for the well-being of their families, and for communities. Areas where organized crime is allowed to flourish may experience an increase in a number of adverse health events and conditions, from homicide (Fagan, Wilkinson, \& Davies, 2007), to suicide (Fagan \& Davies, 2004), to drug overdose (Davey-Rothwell, Siconolfi, Tobin, \& Latkin, 2015). One of the most virulent criticisms of anti-trafficking efforts has been that the U.S. Department of State overestimates the number of victims in the country (Weitzer, 2015). One possibility is that the number of victims has not been overestimated, but that the majority remain undetected by law enforcement (Farrell et al., 2010), which has been the principal entity charged with their identification. Physicians, nurses and other members of the healthcare sector could be crucially important aides to human trafficking victim identification. As others have suggested, contact with the healthcare system may be the only point of contact with a potential source of help that many trafficked individuals have (Sabella, 2011). However, because only a small proportion of US and UK based healthcare professionals (Chisolm-Straker et al., 2012) (Ross et al., 2015), have ever received any training in human trafficking, much more could be done to prepare the healthcare system to assist with human trafficking intervention.

The present study relayed the reactions of 10 healthcare providers and administrators who were involved in the development one of the first healthcare system protocols in the U.S. for the identification, assessment, treatment and referral of victims of human trafficking. The process that the developers of the protocol undertook was involved and resource-intensive; numerous staff people spent a substantial amount of time consulting existing evidence and 
recommendations, receiving advice from national and local experts, and vetting the draft protocol with the healthcare system legal department and local law enforcement specialists. After field-testing and updating the protocol, and creating online and in-person trainings to explain how to use it, the developers have accumulated several important insights. First, there was universal agreement that the protocol pocket-card is easy to use and a helpful tool. Second, many felt that it was essential that entire multidisciplinary teams - including physicians, nurses, security personnel, patient education specialists, social workers and others-all receive the same training so that they can work together when potential trafficking victimization cases arise. It was emphasized that a sole individual who has been trained to recognize trafficking is unlikely to be able to act on behalf of the patient, because no single provider has all of the skills and knowledge necessary to be successful. Without a robust network of acute and long-term resources including housing, mental health service provision, substance abuse treatment, and legal services survivors may quickly return to their exploitation. Third, hospitals and other healthcare organizations that choose to participate in human trafficking intervention and prevention should be prepared to engage community service providers, such as substance abuse treatment centers, behavioral health agencies, housing assistance programs, etc. in order to ensure that once they are identified, trafficking survivors have a "next step" to take towards health and rehabilitation. Also important is ensuring that local providers are trauma-informed and feel prepared to meet the specialized needs of trafficking survivors. A lack of local services, or a lack of trauma-informed and prepared local providers, can pose an ethical quandry for healthcare professionals because it could endanger or harm a victim to be identified but then receive inadequate follow-up help. One possibility is that providers adapt the "coordinated community response" model that domestic violence providers have used throughout the 
U.S.(Shepard, Falk, \& Elliott, 2002; Shorey, Tirone, \& Stuart, 2014). More information about the coordinated community response can be found here: http://www.stopvaw.org/coordinated_community_response .

This protocol was developed broadly to be used by any type of clinician — that is, physicians, nurses, physician assistants, social workers, or others. A general-use version of the protocol makes sense, because signs of possible victimization are universal and should be recognized by any healthcare provider providing trauma-informed care (SAMHSA, 2014). However, it is also true that use of the protocol may become more common and more effective if it is tailored for specific settings. In the time that has elapsed between the conduct of this study and this publication, the healthcare system has developed a new version of the protocol for pediatric care providers. Differences in pediatric protocol compared to the original are that the indicators are specific to sexual exploitation, and include specific physiological and behavioral signs such as frequent urinary tract infections and precocious sexual behavior. Additional adaptations of the protocol for other specific settings (e.g., obstetrics and gynecology, family medicine, emergency medicine) may also be useful.

A prior review of the literature identified 27 toolkits, handbooks, online training courses, informational websites, articles and other materials that could be used to train healthcare providers about human trafficking (Ahn et al., 2013). To our knowledge, there are no data about how commonly any of these materials are used and there are no publicly accessible education modules that have been rigorously evaluated. Although the module is not publicly available, Grace et al., recently conducted a group randomized controlled trial examining the effectiveness of a standardized educational presentation about human trafficking in the 20 largest emergency departments in the San Francisco (SF) Bay Area, and found that the training improved clinicians' 
knowledge about trafficking and what to do if they identified a victim (Aimee M. Grace et al., 2014). Moreover, the U.S. Department of Health and Human Services is presently evaluating a different training for healthcare professionals about assisting trafficking victims called SOAR to Health and Wellness (Rollins, 2015), and two authors on this article are evaluating a training for emergency medicine personnel (i.e., ambulance care providers and paramedics). Outcome evaluations of the implementation of hospital and health center guidelines, and clinician training modules, represent important next steps for the field. Advocating for healthcare professionals' training on human trafficking will be easier and more reasonable once there is evidence to support the idea that the training improves participants' knowledge and skills, results in the better identification and treatment of trafficking victims, and ultimately improves public safety and public health.

This study is subject to several limitations. This was a small-scale, qualitative study designed to relay subjective opinions about the use of a healthcare system human trafficking protocol. It was not designed to be representative of all clinicians in this healthcare system, as the aim of qualitative research is not to produce generalizable results (Clark, 2003). One potential limitation of the methods is that the research assistants hand-copied notes during interviews with study participants rather than audio-recording and transcribing. However, because the objective of this study was to capture the primary thoughts and feelings of the participants, and was not ethnographic, the verbatim utterances of the participants was not critical to the analysis. However, any future studies that seek to evaluate rigorously providers' and administrators' experiences with this or another protocol should use a more precise method. A second limitation is that because this study was not designed to produce generalizable results, other hospitals or healthcare organizations that choose to create pocket-cards or establish 
protocols based on this example may have different experiences. The idea that different experiences may be had in different places is not unique to this study, however, and perhaps should not be viewed as a weakness of the present study but as a caution about proceeding locally with an open outlook. 


\section{References}

Ahn, R., Alpert, E. J., Purcell, G., Konstantopoulos, W. M., McGahan, A., Cafferty, E., .. . Burke, T. F. (2013). Human Trafficking Review of Educational Resources for Health Professionals. American Journal of Preventive Medicine, 44(3), 283-289. doi:10.1016/j.amepre.2012.10.025

Baldwin, S. B., Eisenman, D. P., Sayles, J. N., Ryan, G., \& Chuang, K. S. (2011). Identification of human trafficking victims in health care settings. Health and Human Rights, 13(1), 3649. Retrieved from $<$ Go to ISI $>$ ://WOS:000208960600007

Barrows, J. (2015). [Personal communication about the estimated proportion of U.S. hospitals with guidelines for the identification of human trafficking victims in place ].

Becker, H. J., \& Bechtel, K. (2015). Recognizing Victims of Human Trafficking in the Pediatric Emergency Department. Pediatric Emergency Care, 31(2), 144-147. doi:10.1097/pec.0000000000000357

Chisolm-Straker, M., Richardson, L., \& Cossio, T. (2012). Combating Slavery in the 21st Century: The Role of Emergency Medicine. Journal of Health Care for the Poor and Underserved, 23(3), 980-987. Retrieved from < Go to ISI $>$ ://WOS:000307425800009

Clark, J. (2003). How to peer review a qualitative manuscript. In F. Godlee \& T. Jefferson (Eds.), Peer Review in Health Sciences. London: BMJ Books.

Davey-Rothwell, M. A., Siconolfi, D. E., Tobin, K. E., \& Latkin, C. A. (2015). The role of neighborhoods in shaping perceived norms: An exploration of neighborhood disorder and norms among injection drug users in Baltimore, MD. Health \& Place, 33, 181-186. doi:10.1016/j.healthplace.2015.03.009 
Ernewein, C., \& Nieves, R. (2015). Human Sex Trafficking: Recognition, Treatment, and Referral of Pediatric Victims. Jnp-Journal for Nurse Practitioners, 11(8), 797-803. doi:10.1016/j.nurpra.2015.06.005

Fagan, J., \& Davies, G. (2004). The Natural History of Neighborhood Violence. Journal of Contemporary Criminal Justice, 20(2), 127-147. doi:10.1177/1043986204263769

Fagan, J., Wilkinson, D. L., \& Davies, G. (2007). Social contagion of violence. In D. J. Flannery, A. T. Vazsonyi, I. D. Waldman, D. J. Flannery, A. T. Vazsonyi, \& I. D. Waldman (Eds.), The Cambridge handbook of violent behavior and aggression. (pp. 688-723). New York, NY, US: Cambridge University Press.

Farrell, A., McDevitt, J., \& Fahy, S. (2010). Where are all the victims? Understanding the determinants of official identification of human trafficking incidents. Criminology \& Public Policy, 9(2), 201-233. doi:10.1111/j.1745-9133.2010.00621.x

Grace, A. M., Ahn, R., \& Konstantopoulos, W. M. (2014). Integrating Curricula on Human Trafficking Into Medical Education and Residency Training. Jama Pediatrics, 168(9), 793-794. doi:10.1001/jamapediatrics.2014.999

Grace, A. M., Lippert, S., Collins, K., Pineda, N., Tolani, A., Walker, R., . . Horwitz, S. M. (2014). Educating Health Care Professionals on Human Trafficking. Pediatric Emergency Care, 30(12), 856-861. doi:10.1097/PEC.0000000000000287

Hsieh, H.-F., \& Shannon, S. E. (2005). Three Approaches to Qualitative Content Analysis. Qualitative Health Research, 15(9), 1277-1288. doi:10.1177/1049732305276687 International Labor Organization. (2015). Statisics and indicators on forced labour and trafficking. Retrieved from http://www.ilo.org/global/topics/forced-labour/policyareas/statistics/lang--en/index.htm 
Konstantopoulos, W. M., Ahn, R., Alpert, E. J., Cafferty, E., McGahan, A., Williams, T. P., . . Burke, T. F. (2013). An International Comparative Public Health Analysis of Sex Trafficking of Women and Girls in Eight Cities: Achieving a More Effective Health Sector Response. Journal of Urban Health-Bulletin of the New York Academy of Medicine, 90(6), 1194-1204. doi:10.1007/s11524-013-9837-4

Lederer, L., \& Wetzel, C. (2014). The health consequence of sex trafficking and the implications for identifying victims in healthcare facilities. Annals of Health Law, 21(1), 61-91.

Peters, K. (2013). The growing business of human trafficking and the power of emergency nurses to stop it. Journal of Emergency Nursing, 39(3), 280-288. doi:10.1016/j.jen.2012.03.017

President's Interagency Task Force to Monitor and Combat Trafficking in Persons. (2013). Federal Strategic Action Plan on Services for Victims of Human Trafficking in the United States 2013-2017. Retrieved from Washington, DC: http://www.ovc.gov/pubs/FederalHumanTraffickingStrategicPlan.pdf

Rollins, R. (2015, November 4, 2015). SOAR to Health and Wellness: A New Federal Training on Human Trafficking for Health Care Providers. Paper presented at the American Public Health Association's Annual Meeting 2015, Chicago, IL.

Ross, C., Dimitrova, S., Howard, L. M., Dewey, M., Zimmerman, C., \& Oram, S. (2015). Human trafficking and health: a cross-sectional survey of NHS professionals' contact with victims of human trafficking. Bmj Open, 5(8). doi:10.1136/bmjopen-2015-008682

Sabella, D. (2011). The Role of the Nurse in Combating Human Trafficking. American Journal of Nursing, 111(2), 28-37. doi:10.1097/01.NAJ.0000394289.55577.b6 
SAMHSA. (2014). SAMHSA's Concept of Trauma and Guidance for a Trauma-Informed Approach. Retrieved from Washington, DC: http://store.samhsa.gov/shin/content/SMA14-4884/SMA14-4884.pdf

Shepard, M. F., Falk, D. R., \& Elliott, B. A. (2002). Enhancing coordinated community responses to reduce recidivism in cases of domestic violence. Journal of Interpersonal Violence, 17(5), 551-569. doi:10.1177/0886260502017005005

Shorey, R. C., Tirone, V., \& Stuart, G. L. (2014). Coordinated community response components for victims of intimate partner violence: A review of the literature. Aggression and Violent Behavior, 19(4), 363-371. doi:10.1016/j.avb.2014.06.001

Stoklosa, H., Grace, A., \& Littenberg, N. (2015). Medical Education on Human Trafficking. AMA Journal of Ethics, 10, 914-921. doi:doi: 10.1001/journalofethics.2015.17.10.medu11510

The White House. (2015). End Trafficking. Retrieved from https://www.whitehouse.gov/issues/foreign-policy/end-human-trafficking

U.S. Department of State. (2014). Trafficking in persons report. Retrieved from Washington, DC: http://www.state.gov/documents/organization/226844.pdf

U.S. Department of State. (2015). Trafficking in persons report. Retrieved from http://www.state.gov/documents/organization/245365.pdf

Weitzer, R. (2014). New Directions in Research on Human Trafficking. Annals of the American Academy of Political and Social Science, 653(1), 6-24. doi:10.1177/0002716214521562

Weitzer, R. (2015). Human trafficking and contemporary slavery. In K. S. Cook \& D. S. Massey (Eds.), Annual Review of Sociology, Vol 41 (Vol. 41, pp. 223-242). Palo Alto: Annual Reviews. 


\section{Appendix}

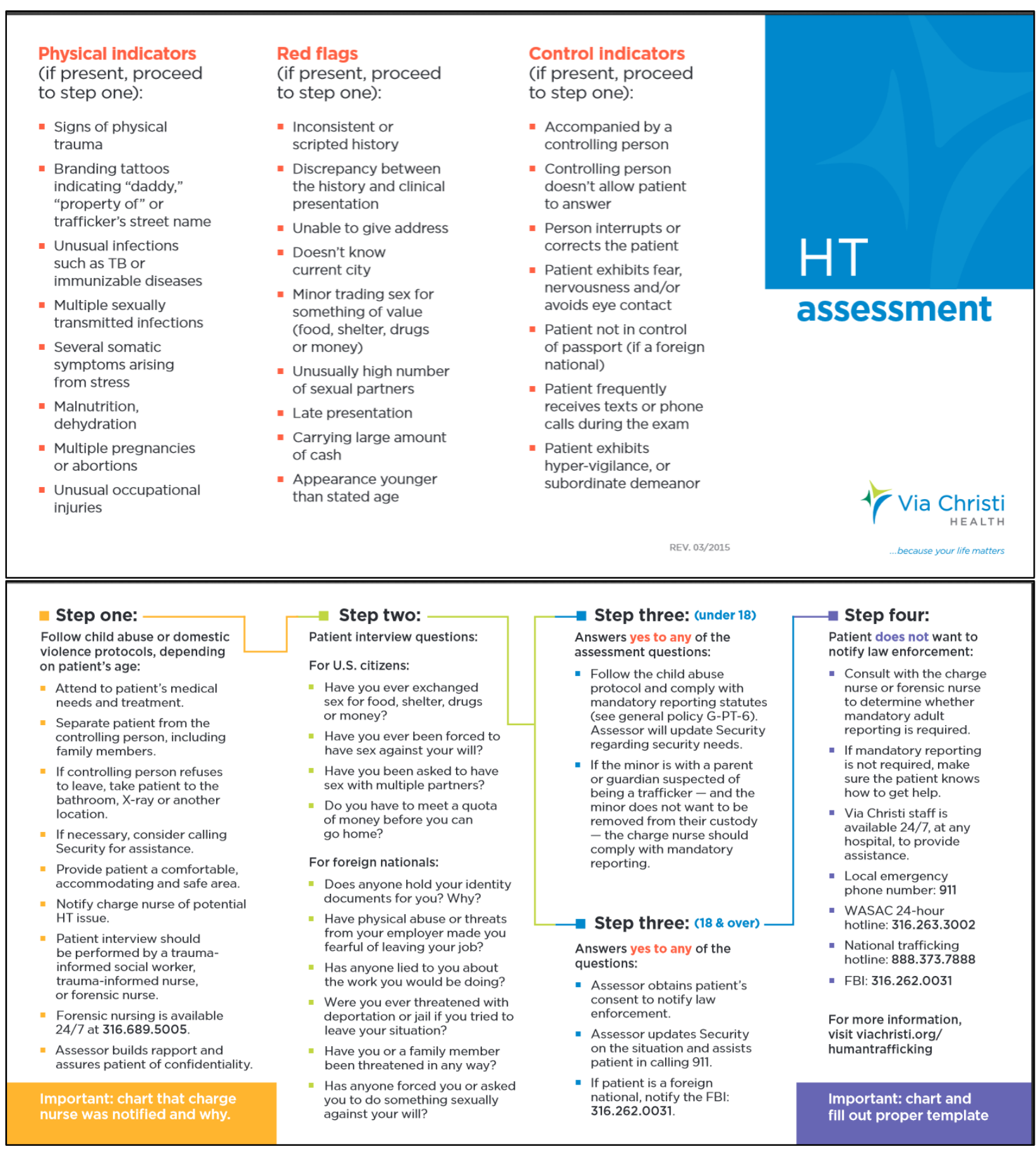

https://www.viachristi.org/sites/default/files/pdf/about us/2015-0625\%20Human\%20trafficking\%20assessment web.pdf

Caution: If this is prematurely implemented without the proper structure and training the victim, healthcare professional, and everyone in the environment could be put in danger. 